\title{
A prospective study of socio-demographic, clinical characteristics and treatment outcomes of children with tuberculosis in Sindh, Pakistan
}

\author{
Madeeha Laghari ${ }^{1 *}$ (D) Syed Azhar Syed Sulaiman ${ }^{1}$, Amer Hayat Khan ${ }^{1}$ and Naheed Memon ${ }^{2}$
}

\begin{abstract}
Background: Understanding the explanations behind unsuccessful treatment outcomes in tuberculosis (TB) patients is important to improve treatment success. Treatment completion for TB is the mainstay of TB prevention and control. The study was aimed to assess the treatment outcomes and predictors for unsuccessful outcomes among children with TB.

Methods: This was a prospective multicenter study conducted in Sindh. Children aged $\leq 14$ years enrolled from June to November 2016 were included. A structured data collection tool was used to gather information with respect to patients' socio-demographic, clinical and microbiological data. Additionally, to collect the information related to socio-economic and education level of caregivers, validated questionnaire was administered to the caregivers. Treatment outcomes were assessed according to the World Health Organization (WHO) guidelines. The relationship of unsuccessful treatment outcome with socio-demographic and clinical attributes of TB patients was analyzed using logistic regression model.
\end{abstract}

Results: Childhood TB represented 19.3\% (508/2634) of all TB cases in selected hospitals. Of these, 268/508 (52.8\%) were females and one third of the children were aged $\leq 2$ years (34.3\%). In multivariate analysis, pulmonary smear positive $\mathrm{TB}(\mathrm{PTB}+)(\mathrm{AOR}=5.910,95 \% \mathrm{Cl}=1.64-21.29)$, those with adverse drug reactions $(\mathrm{AOR}=11.601$, $95 \% \mathrm{Cl}=4.06-33.12)$ and those who had known $\mathrm{TB}$ contacts $(\mathrm{AOR}=3.128,95 \% \mathrm{Cl}=1.21-8.06)$ showed statistically significant association with unsuccessful treatment outcomes.

Conclusions: The high proportion of childhood TB cases (19.3\%) demonstrates the continuation of TB transmission in the study setting. Furthermore, an increased focus on PTB+ patients, those with adverse drug reactions and household contact with TB is warranted.

Keywords: Tuberculosis, Treatment outcomes, Pulmonary TB, Children $\leq 14$ years, Pakistan

\section{Background}

The principal objectives of TB treatment are to cure the individual with the disease and limit the transmission of Mycobacterium tuberculosis (M. tuberculosis) to others in the community [1]. The World Health Organization (WHO) suggests Directly Observed Therapy Short (DOTS) and has set curative thresholds of $85 \%$ [2]. The

\footnotetext{
* Correspondence: madeehalaghari@gmail.com

${ }^{1}$ Department of Clinical Pharmacy, School of Pharmaceutical Sciences,

Universiti Sains Malaysia, 11800 Minden Penang, Malaysia

Full list of author information is available at the end of the article
}

principle pointers used to measure advance in execution of DOTS are the availability of a National Tuberculosis Control Programme (NTP) manual consistent with the DOTS strategy, the number of administrative sectors in the country performing the new TB control system, the treatment cure and success rate in new smear positive cases, and the case detection rate [3].

In 2016, 51,000 (9.8\%) of an estimated 518,000 TB cases notified in Pakistan, were children aged $\leq 14$ years [4]. During the same year, a total of 41,758 cases of childhood TB were reported with the NTP [5]. There is

(C) The Author(s). 2019 Open Access This article is distributed under the terms of the Creative Commons Attribution 4.0 International License (http://creativecommons.org/licenses/by/4.0/), which permits unrestricted use, distribution, and 
evidence that in these settings most of the TB cases were being missed in large hospitals particularly in Tertiary Care Hospitals where most of the presumptive TB cases go unrecognized, the diagnosed and treated cases are not reported to the NTP or the treatment may not follow national guidelines [5].

In 2015, the treatment success rate in new and relapse cases in Pakistan was reported as 93\% [4]. Treatment outcome at the end of therapy is an important marker of TB control programmes [6]. Moreover, examining and assessment of treatment outcomes of TB patients is an essential element of the DOTS strategy [7].

To the best of our knowledge, risk factors for poor treatment outcomes have not previously been evaluated among children in Pakistan. Furthermore, this was the first time that the rate and proportion of TB was studied among children at the study site. The study was conducted to highlight the issue of increasing trend of childhood TB. The objectives of the study were to describe the proportion of childhood TB cases, treatment outcomes and the possible risks of treatment failure in children aged $\leq 14$ years.

\section{Methods}

\section{Study settings and design}

This prospective observational study of TB in children $\leq 14$ years of age was conducted over a period of 18 months. The study was conducted in the following public sector hospitals:

i. Liaquat University of Medical and Health Sciences Civil Hospital, Hyderabad (LUMHS-CHH).

ii. Sindh Government Hospital Qasimabad, Hyderabad (SGH-QH).

iii. Shah Bhitai Government Hospital, Latifabad, Hyderabad (SBGH-LH).

iv. Jamshoro Institute of Chest Diseases Kotri, Sindh (ICDK).

v. Matiari Syed Baqadar Shah Taluka Hospital, Matiari (SBS-THM).

Children diagnosed with TB from 1 June 2016 through 30 November 2016 were consecutively enrolled and followed up monthly until the end of treatment. Children with drug-resistant TB and comorbidities were excluded. Verbal consent was sought from all guardians or caregivers (mostly parents) of patients.

\section{Data collection}

A standardized data collection form was used to collect the information of patients regarding their socio-demographic, microbiological and clinical data. The socio-demographic variables included: age, gender, residence, body weight at baseline and monthly follow-up visits, level of education and monthly income of their treatment supporter and household contacts (HHC) with TB. Microbiological data consisted of sputum smear microscopy of acid fast bacilli (AFB) and Gene Xpert MTB/RIF (Xpert MTB/RIF) (Cepheid., New Jersey, USA) results at baseline. Clinical data contained category of TB at the start (new, relapse, lost to follow-up, failure), types of TB (pulmonary or extra-pulmonary), laboratory results and radiological findings of chest X-ray (CXR) at baseline and subsequent monthly visits (if recommended by clinician), Pakistan Pediatric Association (PPA) score, Bacillus Calmette-Guerin (BCG) scar, treatment regimen, adverse drug reactions (ADRs) and treatment outcomes of anti-tuberculosis Treatment (ATT). Body weight and age was used to determine weight for age using data table of weight for age charts of Centres for Disease Control and Prevention (CDC). Patients with weight $<5$ th percentile were recorded as underweight and those with $\geq 95$ th percentile weight for age were considered as overweight [8]. Logistic regression model was used to analyze the predictors for unsuccessful treatment outcomes. Factors found significant in univariate analysis, were included in multivariate logistic regression to estimate the odds ratios (ORs) with their 95\% confidence intervals (CIs). $P$ value $<0.05$ was considered statistically significant. All the factors considered in the univariate analysis were based on literature review and suggestions from the clinical team.

\section{Diagnosis}

Children were diagnosed as having TB considering suggestive clinical features, history of TB contact, a positive tuberculin skin test (TST) result, PPA scoring charts (suggested by Pakistan Paediatric Association) $>7$ score and evidence of TB on CXR for pulmonary TB (PTB). Mycobacterial culture and Xpert MTB/RIF assays were used as add-on tests and specifically performed to exclude drug resistant-TB. Children presenting to the hospitals with clinical symptoms including cough lasting for $\geq 2$ weeks, fever, night sweat, dyspnea, weight loss, sputum production and those indicative of extra-pulmonary TB (EPTB) were evaluated for TB. TST was done using standard of 5 Tuberculin Units (TU in 0.1 $\mathrm{mL}$ ) (Sanofi Pasteur, Toronto, Canada), during the initial visit and read at $48-72 \mathrm{~h}$. Since children were being evaluated for TB, a TST $\geq 10 \mathrm{~mm}$ induration was considered positive [9]. Fluorescence microscopy was used for sputum smear samples for the presence of AFB. In addition, Xpert MTB/RIF assay is routinely done in sputum smear negative and sputum smear positive patients for further confirmation of $M$. tuberculosis and drug-resistance TB based on NTP guidelines [10]. For EPTB, diagnostic tests were performed depending on the sites involved. CXR was done in all EPTB cases to exclude the pulmonary involvement. Fine needle 
aspiration cytology (FNAC) was the first-line diagnostic technique for the peripheral lymph nodes. However, if the FNAC examination results were inconclusive, excision biopsy was done for definitive diagnosis. Fluid specimens (pleural, cerebrospinal fluid, gastric aspirate, synovial) were subjected to microscopy, culture, Xpert MTB/RIF and biochemical analysis. Diagnosis of skin TB was more complex and consequently different tests were performed to ascertain the diagnosis including fluorescent microscopy, tissue culture and skin biopsy with histological analysis. The total duration of treatment for category-I (new patients) was 6 months whereas for category-II (relapse, lost to follow-up, and failure with previous TB treatment) the duration was 8 months as stated in national guidelines. Patients diagnosed with EPTB and PTB concomitantly were grouped under PTB based on NTP guidelines [10]. PTB refers to any bacteriologically confirmed or clinically diagnosed case of TB involving the lung parenchyma or the tracheobronchial tree. Miliary TB is classified as PTB because there are lesions in the lungs. EPTB refers to any bacteriologically confirmed or clinically diagnosed case of TB involving organs other than the lungs, e.g. pleura, lymph nodes, abdomen, genitourinary tract, skin, joints and bones, meninges [11]. According to $\mathrm{WHO}$ guidelines [9], patients who were stated "cured" and/or "completed treatment" were termed as "treatment success", and all those patients who were lost to follow-up, died, or treatment failure were reported under a category of "unsuccessful treatment". A cured patient was a bacteriologically confirmed PTB patient who became smear negative in the last month of treatment and on at least one previous occasion. Treatment completed included TB patients who completed treatment with no record to show smear negative in the last month of treatment and on at least one previous occasion.

\section{Results}

\section{Proportion of childhood TB cases}

From 1st June to 1st November 2016, childhood TB added up to 508 out of 2634 (19.3\%) of all TB cases in five selected districts namely Hyderabad, Jamshoro and Matiari. All 508 patients met the inclusion criteria and were enrolled in the study. Overall, the highest numbers of children with TB $(274 ; 54 \%)$ were registered in ICDK. In Hyderabad, the maximum numbers of patients were registered at LUMHS-CHH $(145 ; 28.5 \%)$ compared to SGH-QH $(15 ; 3 \%)$ and SBGH-LH, $(22 ; 4.3 \%)$ whereas 52; $10.2 \%$ cases were reported in SBS-THM.

Socio-demographic and baseline clinical characteristics of children with TB

The number and proportion of patients with TB during the study period are presented in Table 1. Of these, 268
(52.8\%) were females and 240 (47.2\%) were males with median age of 4 with interquartile range of 2-8 years. Based on the diagnostic results, 396 (78\%) patients had pulmonary TB (PTB) and $112(22 \%)$ had EPTB. Of EPTB cases, most cases (38.4\%) had peripheral lymphadenitis. All sputum smear cases were repeated on Xpert MTB/RIF assay for further confirmation of $M$. tuberculosis in PTB- and resistance $\mathrm{TB}$ in $\mathrm{PTB}+$. There were three cases which had negative results in sputum microscopy but were found positive on Xpert MTB/RIF test. Regarding therapeutic categorization, 485/508 (95.5\%) children were enrolled as new cases while 23/ 508 (4.5\%) were reported as retreatment cases. Seventy-two (14.2\%) had no BCG scar. HIV test was done in all children and none were HIV-positive.

\section{Baseline symptoms of TB in children}

Cough $(349 / 508,68.7 \%)$ and weight loss $(325 / 508,64 \%)$ were the most frequently observed symptoms among the patients. Beside this, 277/508 (54.5\%) patients had fever. Seizure (17/508, 3.3\%), vomiting (18/508, 3.7\%) and abdominal pain $(21 / 508,4.1 \%)$ were reported in patients with meningitis and abdominal TB. Caregivers of 188/ 508 (37\%) of the patients complained of decreased physical activity.

\section{Laboratory values at baseline visit}

The laboratory characteristics of the patients are summarized in Table 2 . Twenty three percent and $36.8 \%$ of patients had increased lymphocyte and Erythrocyte Sedimentation Rate (ESR) value, respectively. The monocyte to lymphocyte ratio (MLR) was $0.23 \pm 0.11$ and Neutrophil to Lymphocyte Ratio (NLR) was $6.71 \pm 0.16$. During evaluation, a significant positive correlation was observed in NLR and ESR.

\section{Frequency of EPTB among study participants}

Of 112 cases of EPTB, the most common site of EPTB was the lymph nodes frequently seen among children aged 6 to 14 years old (Table 3 ). Those aged $\leq 2$ years had higher proportion of meningitis. Females were presented with significantly higher cases of lymph node TB (40.7\%) compared to other types of EPTB while frequency of abdominal and skin TB was higher in male patients. Residence, BCG scar and TST were significantly associated with types of EPTB.

\section{Association of socio-demographic and clinical characteristics with treatment outcomes}

Summary of treatment outcomes is given in Table 4. Of the 508 children in the study, 483 (95.1\%) achieved successful treatment outcomes with $90.7 \%$ of complete adherence to the treatment; 15 (3\%) were cured and 468 (92.1\%) completed treatment. Of those with unfavourable outcomes, 6 (1.2\%) died, $4(0.8 \%)$ failed treatment, $9(1.8 \%)$ were lost to 
Table 1 Socio-demographic and clinical characteristics of children with TB in Hyderabad, Matiari and Jamshoro districts of Pakistan $(n=508)$

\begin{tabular}{ll}
\hline Variables & $n(\%)$ \\
\hline Gender & $240(47.2)$ \\
Male & $268(52.8)$ \\
Female & \\
Age (years) & $174(34.2)$ \\
$\leq \leq 2$ & $120(23.6)$ \\
$3-5$ & $139(27.4)$ \\
6-10 & $75(14.8)$ \\
11-14 & \\
Residence & $206(40.6)$ \\
Rural & $302(59.4)$ \\
Urban & \\
Type of TB & $29(5.7)$ \\
PTB+ & $52(10.2)$ \\
PTB- & $315(62.0)$ \\
PTBNS & $112(22.0)$ \\
EPTB & \\
EPTB site & \\
Peripheral lymph & \\
nodes & \\
Abdominal & \\
Pleural & \\
Bones/Joints & $14(12.5)$ \\
Meningitis & $1(0.9)$ \\
Skin & \\
Weight (percentiles) & \\
\hline & \\
\hline
\end{tabular}

Underweight $\quad 457(90.0)$

Normal* $\quad 51(10.0)$

Registration category

New

Retreated

BCG scar

Present

Absent

Baseline CXR

Normal

Abnormal

Not done

TST

Positive ( $\geq 10 \mathrm{~mm})$

Negative $(<10 \mathrm{~mm})$

${ }^{*}<5$ percentiles, $\mathrm{PTB}-=$ smear negative pulmonary TB,

PTB+ smear positive pulmonary TB, PTBNS pulmonary TB

with no sputum examination, EPTB extra-pulmonary $\mathrm{TB}$,

TST Tuberculin Skin Test, and BCG Bacillus Calmette-Guerin

* include relapse, Lost to follow-up and failure patients with previous

TB treatment

CXR Chest X-ray

$436(85.8)$

$72(14.2)$

$131(25.8)$

318 (62.6)

$59(11.6)$

$268(52.8)$

$240(47.2)$
Table 2 Laboratory values of patients at baseline visit $(n=487)$

\begin{tabular}{|c|c|c|}
\hline Variables & Mean $\pm S D$ & $n(\%)$ \\
\hline \multicolumn{3}{|l|}{ Hemoglobin } \\
\hline Normal (13-16 g/dL) & $8.9 \pm 1.9$ & $21(4.3)$ \\
\hline Below normal & & $466(95.7)$ \\
\hline \multicolumn{3}{|l|}{ RBCs } \\
\hline Normal (3.8-5.9 millions $\left./ \mathrm{mm}^{3}\right)$ & $4.15 \pm 0.7$ & $286(58.7)$ \\
\hline Below normal & & $178(36.6)$ \\
\hline Above normal & & $23(4.7)$ \\
\hline \multicolumn{3}{|l|}{ Lymhocytes } \\
\hline Normal (20-45\%) & $32 \pm 17.7$ & $253(52)$ \\
\hline Below normal & & $121(24.8)$ \\
\hline Above normal & & $113(23.2)$ \\
\hline \multicolumn{3}{|l|}{ Monocytes } \\
\hline Normal (02-10\%) & $7.4 \pm 2.1$ & $470(96.6)$ \\
\hline Below normal & & $8(1.6)$ \\
\hline Above normal & & $9(1.8)$ \\
\hline \multicolumn{3}{|l|}{ Neutrophils } \\
\hline Normal (40-75\%) & $49.7 \pm 19.4$ & $270(55.4)$ \\
\hline Below normal & & $43(8.8)$ \\
\hline Above normal & & $174(35.7)$ \\
\hline \multicolumn{3}{|l|}{ ESR } \\
\hline Normal $(20 \mathrm{~mm} / \mathrm{hr})$ & $37.32 \pm 43$ & $264(52)$ \\
\hline Above normal & & $187(36.8)$ \\
\hline Not available & & $57(11.2)$ \\
\hline
\end{tabular}

follow-up and 6 (1.2\%) were transferred out to other units as MDR-TB. Of the retreatment patients 18 of $21(86 \%)$ completed 8 months of treatment, while 2 died. Of the new cases $465 / 481$ (96.7\%) completed their 6 months treatment regimen while 4 died.. Of the 6 patients who died, 1 died during the 1st month of treatment, 4 in 2nd month and 1 in 3rd month. As per decision of panel of physician and paediatricians, TB was the immediate cause of death in all 6 patients.

\section{Risk factors for unsuccessful treatment outcomes}

Variables which showed statistically significant association with unsuccessful treatment outcomes in univariate analysis (Table 5) were age group 11 to 14 years $(\mathrm{COR}=$ $3.554, \quad 95 \% \mathrm{CI}=1.50-8.37), \mathrm{PTB}+\quad(\mathrm{COR}=13.022$, $95 \% \mathrm{CI}=5.13-33.04)$, retreatment cases $(\mathrm{COR}=6.458$, $95 \% \mathrm{CI}=2.17-19.15)$, had ADRs $(\mathrm{COR}=10.326$, $95 \% \mathrm{CI}=4.45-23.91)$, patients with known $\mathrm{TB}$ contacts $(\mathrm{COR}=3.808,95 \% \mathrm{CI}=1.68-8.61)$ and caregivers with no formal education $(\mathrm{COR}=4.903,95 \% \mathrm{CI}=1.81-13.27)$.

In multivariate analysis (Table 5), pulmonary smear positive $\mathrm{TB}(\mathrm{PTB}+)(\mathrm{AOR}=5.910,95 \% \mathrm{CI}=1.64-21.29)$, those with adverse drug reactions $(\mathrm{AOR}=11.601,95 \% \mathrm{CI}=4.06-$ 33.12 ) and those who had known TB contact $(\mathrm{AOR}=3.128$, 
Table 3 Types of EPTB among the study participants in the studied hospitals $(n=112)$

\begin{tabular}{|c|c|c|c|c|c|c|c|c|}
\hline Variables & $\begin{array}{l}\text { Lymph node } \\
n=43(\%)\end{array}$ & $\begin{array}{l}\text { Abdominal } \\
n=28(\%)\end{array}$ & $\begin{array}{l}\text { Pleural } \\
n=14(\%)\end{array}$ & $\begin{array}{l}\text { Bones/ Joints } \\
n=1(\%)\end{array}$ & $\begin{array}{l}\text { Meningitis } \\
n=22(\%)\end{array}$ & $\begin{array}{l}\text { Skin } \\
n=4(\%)\end{array}$ & $\begin{array}{l}\text { Total cases } \\
n=112\end{array}$ & $P$ value* \\
\hline \multicolumn{9}{|l|}{ Gender } \\
\hline Male & $19(35.8)$ & $17(32.1)$ & $5(9.4)$ & 00 & $9(17)$ & $3(5.7)$ & $53(47.3)$ & \multirow[t]{2}{*}{0.366} \\
\hline Female & $24(40.7)$ & $11(18.6)$ & $9(15.3)$ & $1(1.7)$ & $13(22)$ & $1(1.7)$ & $59(52.7)$ & \\
\hline \multicolumn{9}{|l|}{ Age (years) } \\
\hline$\leq 2$ & $6(30)$ & $3(15)$ & $2(10)$ & 00 & $9(45)$ & 00 & $20(17.9)$ & \multirow[t]{4}{*}{0.105} \\
\hline $3-5$ & $7(36.8)$ & $5(26.3)$ & $1(5.3)$ & 00 & $5(26.3)$ & $1(5.3)$ & $19(17)$ & \\
\hline $6-10$ & $18(38.3)$ & $17(36.2)$ & $6(12.8)$ & 00 & $4(8.5)$ & $2(4.3)$ & $47(42)$ & \\
\hline $11-14$ & $12(46.2)$ & $3(11.5)$ & $5(19.2)$ & $1(3.8)$ & $4(15.4)$ & $1(3.8)$ & $26(23.1)$ & \\
\hline \multicolumn{9}{|l|}{ Weight (percentiles) } \\
\hline Normal & $11(52.4)$ & $4(19)$ & $2(9.5)$ & 00 & $3(14.3)$ & $1(4.8)$ & $21(18.8)$ & \multirow[t]{2}{*}{0.765} \\
\hline Underweight ${ }^{* *}$ & $32(35.2)$ & $24(26.4)$ & $12(13.2)$ & $1(1.1)$ & $19(20.9)$ & $3(3.3)$ & $91(81.2)$ & \\
\hline \multicolumn{9}{|l|}{ Residence } \\
\hline Rural & $14(29.8)$ & $8(17)$ & $6(12.8)$ & $1(2.1)$ & $16(34)$ & $2(4.3)$ & $47(42)$ & \multirow[t]{2}{*}{0.018} \\
\hline Urban & $29(44.6)$ & $20(30.8)$ & $8(12.3)$ & 00 & $6(9.2)$ & $2(3.1)$ & $65(58)$ & \\
\hline \multicolumn{9}{|l|}{ BCG scar } \\
\hline Present & $35(36.5)$ & $24(25)$ & $14(14.5)$ & $1(1)$ & $18(18.8)$ & $4(4.2)$ & $96(85.7)$ & \multirow[t]{2}{*}{$<0.001$} \\
\hline Absent & $8(50)$ & $4(25)$ & 00 & 00 & $4(25)$ & 00 & $16(14.3)$ & \\
\hline \multicolumn{9}{|c|}{ Registration Category at baseline } \\
\hline New & $41(38.3)$ & $25(23.4)$ & $14(13.1)$ & $1(0.9)$ & $22(20.6)$ & $4(3.7)$ & $107(95.5)$ & \multirow[t]{2}{*}{0.428} \\
\hline Retreated & $2(40)$ & $3(60)$ & 00 & 00 & 00 & 00 & $5(4.5)$ & \\
\hline \multicolumn{9}{|l|}{ TST } \\
\hline Positive ( $\geq 10 \mathrm{~mm}$ ) & $23(53.5)$ & $13(30.2)$ & $3(7)$ & 00 & $4(9.3)$ & 00 & $43(38.4)$ & \multirow[t]{2}{*}{0.019} \\
\hline Negative (<10 mm) & $20(29)$ & $15(21.7)$ & $11(15.9)$ & $1(1.4)$ & $18(26.1)$ & $4(5.8)$ & $69(61.6)$ & \\
\hline
\end{tabular}

*Statistically significant values $\leq 0.05,{ }^{* *}<5$ percentiles

$95 \% \mathrm{CI}=1.21-8.06)$ showed statistically significant association with unsuccessful treatment outcomes.

\section{Follow-up results}

Body weight was recorded for all patients at the follow-up visits. The dose of of the drugs were adjusted according to the weight gain. The Majority of children (95.1\%) were documented to have weight gain to more or equal to the 5 th percentile. At the end of intensive phase sputum smear examination was repeated for PTB + and for them sputum conversion rate was recorded as $80 \%(23 / 29)$. All patients had their CXR examination repeated at the end of the continuation phase. Those who had normal CXR were recorded with successful treatment outcomes together with improved symptoms.

\section{Discussion}

This study is one of few that report data on the patient's profiles and treatment outcomes of TB patients aged $\leq 14$ years enlisted and treated under DOTS in Pakistan. Nineteen percent of total number of TB cases were recorded for childhood TB at the study site. More than half of the cases (57.9\%) were aged $\leq 5$ years and $90 \%$ of children were noted underweight. The study findings however identify certain priority areas that need to be addressed by the National and State health authorities. Majority of participants in the present study were females (52.8\%) but the difference was not significant.

The highest cases of TB in current study were observed among the children aged $\leq 2$ years (34.2\%) and this is in agreement with a previous study conducted in South Africa [12]. The higher rates in young children could be due to increased risk of developing disease after infection compared to older children, a high risk of being infected at a young age in a population with a high $\mathrm{TB}$ incidence is common in developing countries such as Pakistan. The extent of EPTB in current study was $22 \%$ and the most frequent site of EPTB in the present study was the lymph nodes, similar to the findings among children in previous studies [13, 14]. Meningitis was mainly observed in children $<5$ years, this agrees with the study conducted among children in South Africa where $82 \%$ of meningitis cases were seen in children aged $<5$ years [15]. 


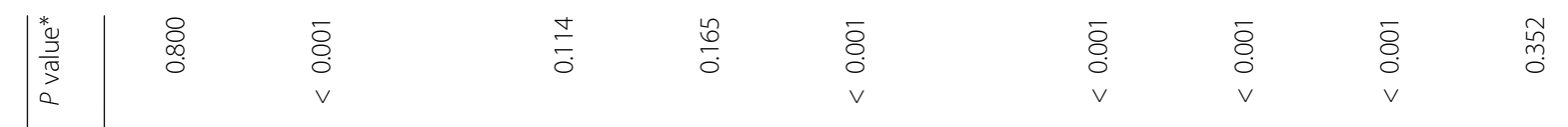

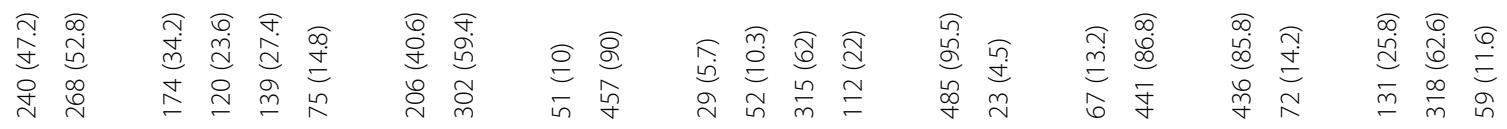

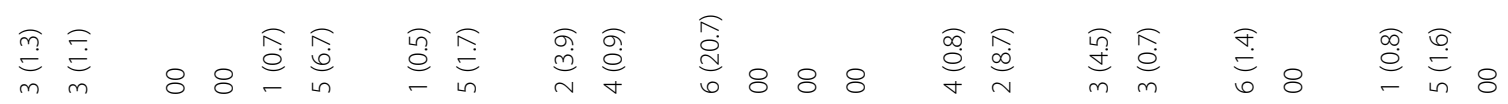

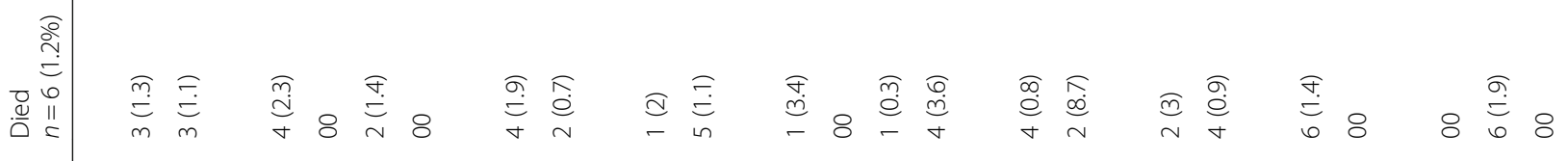

$$
\begin{aligned}
& \text { (1) }
\end{aligned}
$$

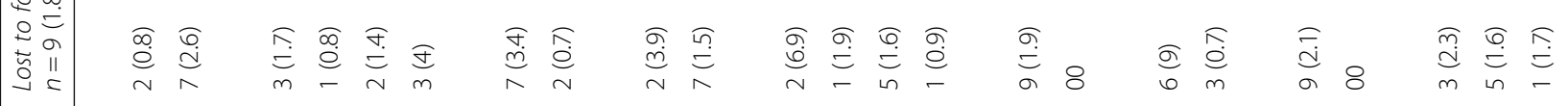

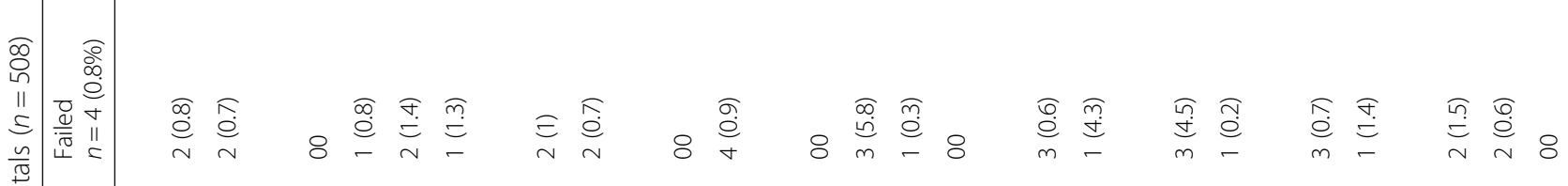

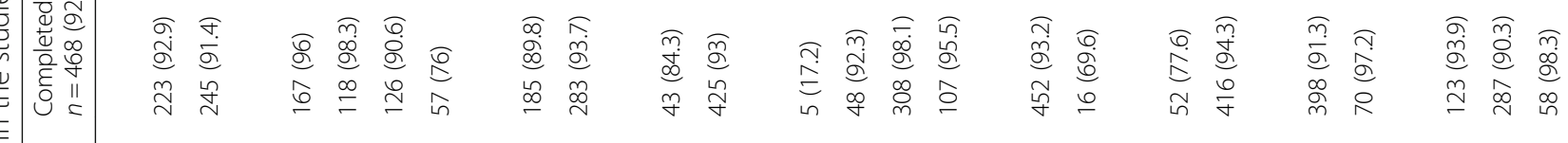


Laghari et al. BMC Infectious Diseases $\quad$ (2019) 19:82

Page 7 of 11

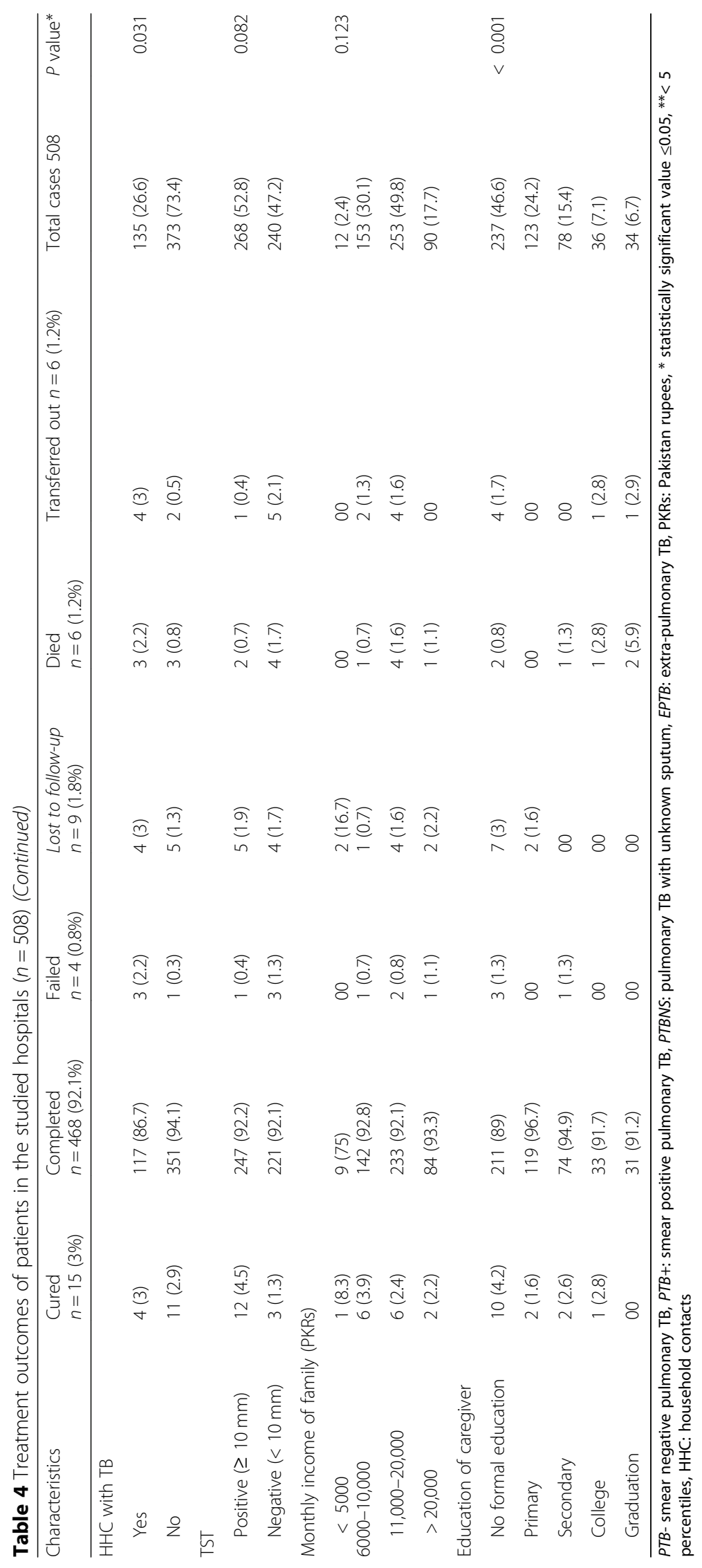


Table 5 Logistic regression analysis of risk factors for unsuccessful treatment outcomes at the study site $(n=508)$

\begin{tabular}{|c|c|c|c|c|c|c|}
\hline \multirow[t]{2}{*}{ Variables } & \multicolumn{2}{|c|}{ Treatment outcomes } & \multirow{2}{*}{$\begin{array}{l}\text { Univariate analysis } \\
\text { COR }(95 \% \mathrm{Cl})\end{array}$} & \multirow[t]{2}{*}{$P$ value* } & \multirow{2}{*}{$\begin{array}{l}\text { Multivariate analysis } \\
\text { AOR }(95 \% \mathrm{Cl})\end{array}$} & \multirow[t]{2}{*}{$P$ value } \\
\hline & Successful $n(\%)$ & Unsuccessful n (\%) & & & & \\
\hline \multicolumn{7}{|l|}{ Gender } \\
\hline Male & $230(95.8)$ & $10(4.2)$ & 1 & 0.485 & - & - \\
\hline Female & $253(94.4)$ & $15(5.6)$ & $1.364(0.60-3.09)$ & & & \\
\hline \multicolumn{7}{|l|}{ Age (years) } \\
\hline$\leq 2$ & $167(96)$ & $7(4)$ & 1 & 0.501 & - & - \\
\hline $3-5$ & $118(98.3)$ & $2(1.7)$ & $0.269(0.06-1.15)$ & 0.078 & - & - \\
\hline $6-10$ & $132(95)$ & $7(5)$ & $1.034(0.42-2.53)$ & 0.942 & - & - \\
\hline $11-14$ & $66(88)$ & $9(12)$ & $3.554(1.50-8.37)$ & 0.004 & $2.908(0.78-10.77)$ & 0.110 \\
\hline \multicolumn{7}{|l|}{ Residence } \\
\hline Rural & $192(93.2)$ & $14(6.8)$ & $1.929(0.85-4.33)$ & 0.112 & - & - \\
\hline Urban & $291(96.4)$ & $11(3.6)$ & 1 & & & \\
\hline \multicolumn{7}{|l|}{ Type of TB } \\
\hline PTB+ & $20(69)$ & $9(31)$ & $13.022(5.13-33.04)$ & $<0.001$ & $5.910(1.64-21.29)$ & 0.007 \\
\hline PTB- & $48(92.3)$ & $4(7.7)$ & $1.726(0.56-5.23)$ & 0.335 & - & - \\
\hline PTBNS & $308(97.8)$ & $7(2.2)$ & $0.221(0.09-0.53)$ & 0.001 & $0.771(0.24-2.43)$ & 0.657 \\
\hline EPTB & $107(95.5)$ & $5(4.5)$ & 1 & 0.800 & - & - \\
\hline \multicolumn{7}{|l|}{ Weight(percentiles) } \\
\hline Underweight & $46(90.2)$ & $5(9.8)$ & $2.375(0.85-6.62)$ & 0.098 & - & - \\
\hline Normal & $437(95.6)$ & $20(4.4)$ & 1 & & & \\
\hline \multicolumn{7}{|c|}{ Registration category at baseline } \\
\hline New & $465(95.9)$ & $20(4.1)$ & 1 & 0.001 & $0.368(0.08-1.56)$ & 0.176 \\
\hline Retreated & $18(78.3)$ & $5(21.7)$ & $6.458(2.17-19.15)$ & & $2.720(0.63-11.59)$ & \\
\hline \multicolumn{7}{|l|}{ ADRs } \\
\hline Yes & $53(79)$ & $14(21)$ & $10.326(4.45-23.91)$ & $<0.001$ & $11.601(4.06-33.12)$ & $<0.001$ \\
\hline No & $430(97.5)$ & $11(2.5)$ & 1 & & $0.086(0.03-0.24)$ & \\
\hline \multicolumn{7}{|l|}{ BCG scar } \\
\hline Present & $412(94.5)$ & $24(5.5)$ & 1 & 0.168 & - & - \\
\hline Absent & 71 (98.6) & $1(1.4)$ & $0.242(0.03-1.81)$ & & & \\
\hline \multicolumn{7}{|l|}{ Baseline X-ray } \\
\hline Normal & $125(95.4)$ & $6(4.6)$ & 1 & 0.834 & & \\
\hline Abnormal & $300(94.3)$ & $18(5.7)$ & $1.569(0.64-3.82)$ & 0.323 & - & - \\
\hline Not done & $58(98.3)$ & $1(1.7)$ & $0.305(0.04-2.30)$ & 0.249 & & \\
\hline \multicolumn{7}{|l|}{ TST } \\
\hline Positive ( $\geq 10 \mathrm{~mm}$ ) & $259(96.6)$ & $9(3.4)$ & 1 & 0.091 & - & - \\
\hline Negative $(<10 \mathrm{~mm})$ & $224(93.3)$ & $16(6.7)$ & $2.056(0.89-4.74)$ & & & \\
\hline \multicolumn{7}{|l|}{ HHC with TB } \\
\hline Yes & $121(89.6)$ & $14(10.4)$ & $3.808(1.68-8.61)$ & 0.001 & $3.128(1.21-8.06)$ & 0.018 \\
\hline No & $362(97.1)$ & $11(2.9)$ & 1 & & $0.320(0.12-0.82)$ & \\
\hline \multicolumn{7}{|c|}{ Monthly income of family (PKRs) } \\
\hline$<5000$ & $10(83.3)$ & $2(16.7)$ & $4.113(0.85-19.86)$ & 0.078 & & \\
\hline $6000-10,000$ & $148(96.7)$ & $5(3.3)$ & $0.566(0.20-1.53)$ & 0.264 & & \\
\hline $11,000-20,000$ & $239(94.5)$ & $14(5.5)$ & $1.299(0.57-2.92)$ & 0.526 & - & - \\
\hline$>20,000$ & $86(95.6)$ & $4(4.4)$ & 1 & 0.818 & & \\
\hline
\end{tabular}


Table 5 Logistic regression analysis of risk factors for unsuccessful treatment outcomes at the study site $(n=508)$ (Continued)

\begin{tabular}{|c|c|c|c|c|c|c|}
\hline \multirow[t]{2}{*}{ Variables } & \multicolumn{2}{|c|}{ Treatment outcomes } & \multirow{2}{*}{$\begin{array}{l}\text { Univariate analysis } \\
\text { COR (95\% Cl) }\end{array}$} & \multirow[t]{2}{*}{$P$ value* } & \multirow{2}{*}{$\begin{array}{l}\text { Multivariate analysis } \\
\text { AOR }(95 \% \mathrm{Cl})\end{array}$} & \multirow[t]{2}{*}{$P$ value } \\
\hline & Successful $n(\%)$ & Unsuccessful n (\%) & & & & \\
\hline \multicolumn{7}{|l|}{ Education of caregiver } \\
\hline No formal education & $217(91.6)$ & $20(8.4)$ & $4.903(1.81-13.27)$ & 0.002 & $0.623(0.11-3.30)$ & 0.579 \\
\hline Primary & $121(98.4)$ & $2(1.6)$ & $0.260(0.06-1.12)$ & 0.071 & - & - \\
\hline Secondary & $76(98.7)$ & $1(1.3)$ & $0.223(0.03-1.67)$ & 0.145 & - & - \\
\hline College & 35 (94.6) & $2(5.4)$ & 1 & 0.888 & - & - \\
\hline Graduation & $34(100)$ & 00 & - & - & - & - \\
\hline
\end{tabular}

PTB-: smear negative pulmonary TB, PTB+: smear positive pulmonary TB, PTBNS: pulmonary TB with unknown sputum, EPTB: extra-pulmonary TB, COR: crude odd ratio, AOR: adjusted odd ratio, PKRs: Pakistani rupees, ADRs: Adverse drug reactions, * Statistically significant value $\leq 0.05, H H C$ : household contacts

A remarkable proportion of participants $(90 \%)$ in our study were underweight. Malnutrition is a predefined risk factor for TB in children [16]. Children with TB are by and large observed to be malnourished, and it is common among all ages in Pakistan. Unfortunately, one third of children $<5$ years in Pakistan are underweight, $44 \%$ stunted and $15 \%$ are wasted [17]. Around $32.5 \%$ of family in the present study had a monthly income of $\leq 10,000$ in Pakistan rupees (PKRs) (approximately 75 US dollars), whereas, $50 \%$ reported to have income of $\leq 20,000$ PKRs, demonstrating the very poor and poor status of families, respectively. In addition to poverty, education of parents may have impact on child's health and care, as $46.6 \%$ of caregivers (particularly mothers) of the study cohorts had no formal education. Studies have recognized statistically significant relationship between child malnutrition and mother's education and economic status of family $[18,19]$. At the baseline visit, high proportion (95.7\%) of patients had a hemoglobin level below normal. Haematological anomalies had been used as a diagnostic marker in TB [20]. Presence of anemia in TB patients is a notable fact, documented in number of studies [21, 22]. High proportion of anemia in the current cohort could possibly be related to their socio-economical background. Additionally, patients in the current study were reported with lymphocytopenia and lymphocytosis indicating active TB. Lymphocytopenia specifies TB infection whereas lymphocytosis point towards inflammatory process in TB patients [23, 24]. Previously, the neutrophil count in TB have been positively correlated with increased bacillary count [25]. Nevertheless, in this study neutrophilia was positively associated with CXR abnormalities including bilateral infiltrations and cavitary lesions representing active TB likewise justified by Lyadova [26] where increased neutrophil count represents progression of infection to active TB. Further detailed studies are required to correlate the present hematologic findings in TB children with large sample.

Overall successful treatment outcome (cured and treatment complete) was recorded as $95.1 \%$. Hence, the study site reached the targeted treatment success rate of
$85 \%$ for TB under DOTS set by WHO [27]. Comparable treatment rates for children treated under DOTS have been reported from Ethiopia (85.5\%) [28], South Africa (89.5\%) [29] and Iran (91.7\%) [30]. Treatment success rate in the current cohort of patients was comparatively better than that reported from Malawi (45, 77.3\%) [31, 32], Democratic Republic of Congo (59\%) [33], Botswana (67\%) [34], Ethiopia (77, 78.9\%) [35, 36], Nigeria (79.2\%) [37], Tanzania (79.9\%) [38].

In the present study, $9(1.8 \%)$ patients were lost to follow-up. Of these, 33.3\% were lost to follow-up during first two months and the remaining $66.7 \%$ during the continuous phase of the treatment. Lost to follow-up rate in the study participants was well below the range reported for children in previous studies in different places $5.1-21.1 \%$ [29-31, 33, 36-38]. The low lost to follow-up rate observed in the current cohort could be accredited to the programmatic efforts at the study site to lessen the barriers to care including regular counseling on monthly visits, persistent supply of drugs and tracing patients on phone in case of delay in scheduled monthly visits. Significantly higher lost to follow-up cases were observed in children 11 to 14 years, PTBNS and retreatment cases.

In our study, 6 (1.2\%) patients died during treatment. The mortality rate in our study is consistent with results of earlier studies $(0.7,1.4$ and $1.8 \%)[28,29,33]$ but lower than the rate reported in literature [31, 32, 35, 37-39]. This could be because initiation of treatment was frequently seen within first 2 days of diagnosis. Timely commencement of treatment has been established as the main predictive factor that determines disease fatality and consequences [40]. Significantly increased deaths were reported in children aged $<2$ years similar to the study conducted in Africa [29] and those from rural areas. Because of immature immune system, children especially under 2 years are at a higher risk of death from infectious diseases including TB. Additionally, TB such as TB meningitis is associated with high mortality and is more frequent among young children [39]. Comparing the mortality in patients with types of $\mathrm{TB}$, the proportion was higher in 
EPTB with maximum death cases in meningitis (50\%). The proportions of patients with treatment failure in our study $(0.8 \%)$ are comparable with the previous studies conducted elsewhere [28-30, 33]. Failure of PTB- and PTBNS patients was alarming in this study and may indicate misdiagnosis or incorrect entry of patient.

On multivariate analysis, children with $\mathrm{PTB}+$, ADRs and those had HHC with TB were significant risk factors for unsuccessful treatment outcomes.. Contact with an individual suffering from TB is an important risk factor for TB in children. This factor was significantly associated with unsuccessful treatment outcomes in the present study which is consistent with a previous study [33]. In Iran, household contact was found as the main risk factor for poor treatment outcome in children [30]. Total 135 (26.6\%) children were recorded with household contacts of TB. Of these, 56 (41.5\%) had completed ATT in last 2 years and 79 (58.5\%) were still under treatment. Seven of source cases had MDR-TB, 27 had PTBand 44 were registered as $\mathrm{PTB}+$ with majority of sputum grading +2 . Presence of MDR-TB and PTB+ could have increased the severity of disease in children and increased the risk of poor treatment outcomes in them.

\section{Limitations}

The findings of this study consolidated information of patients with complete information of their treatment outcome at five different hospitals. TB patients transferred to other health facilities were not followed until the end of treatment. In addition, important patient information which could influence TB treatment outcome, including co-morbidity with other chronic illnesses, distance from the treatment center, and adherence level of the caregivers for their child's treatment were not collected and thus not included in the analysis. Sputum microscopy is done in very limited number of children. Furthermore, gastric lavage to acquire sputum among young children for smear microscopy are not frequently used at the study site. Hence, these constraints need to be considered while interpreting the findings.

\section{Conclusion}

The high proportion of childhood TB cases (19.3\%) indicates a high rate of TB transmission in the study area. Additionally, noticeable number of children with $\mathrm{TB}$ was underweight. Keeping in mind to end-up the malnutrition, we recommend that concerned health authorities along with policy stakeholders should take initiatives to control poor nutrition, accelerate the efforts to add fundamental supplements to diet with TB treatment. The risk factors for unsuccessful treatment outcomes in the present study are generally distinguishable before diagnosis or ahead in the course of ATT. TB epidemic cannot be controlled by treating just the active cases with ATT.

\section{Abbreviations}

ADRs: Adverse drug reactions; AFB: Acid-Fast Bacilli; AORs: Adjusted odds ratios; ATT: Anti-tuberculosis treatment; BCG: Bacillus Calmette-Guerin; CDC: Centres for Disease Control and Prevention; Cls: Confidence intervals; COR: Crude odds ratios; CXR: Chest X-ray; DOTS: Directly observed therapy strategy; EPTB: Extra-pulmonary TB; ESR: Erythrocyte sedimentation rate; FNAC: Fine Needle Aspiration Cytology; M. tuberculosis: Mycobacterium tuberculosis; MLR: Monocyte to lymphocyte ratio; NLR: Neutrophil to lymphocyte ratio; NTP: National Tuberculosis Control Program; PKRs: Pakistan rupees; PPA: Pakistan Pediatric Association; PTB: pulmonary TB; PTB: smear negative PTB; PTB +: smear positive PTB; PTBNS: Pulmonary TB with unknown sputum; RBC: Red blood cells; TB: Tuberculosis; TST: Tuberculin skin test; WHO: World Health Organization; Xpert MTB/RIF: Gene Xpert MTB/RIF

\section{Acknowledgements}

The author would like to offer the thanks for School of Pharmaceutical Sciences and Institute of Postgraduate Student for granting the USM Global Fellowship and staff of respective hospitals for their support to conduct this study. We wish to extend our gratitude to Mr. Abubakar Usman, who willingly accepted to read through our manuscript.

Funding

No funding was obtained for this study.

\section{Availability of data and materials}

The datasets used in this study are available from the corresponding author upon reasonable request.

\section{Authors' contributions}

ML and SAS designed the study. NM contributed in acquisition of data. ML analyzed and interpreted the data and drafted the paper. AHK supervised the data analysis. SAS and AHK reviewed the paper critically. All authors read and approved the final paper for publication.

Ethics approval and consent to participate

Ethical approvals were issued by the relevant Institutional Research and Ethics Boards (IREBs) of Shah Bhitae Hospital Latifabad, Hyderabad Liaquat University Hospital Hyderabad / Jamshoro, Sindh Government Hospital Qasimabad, Hyderabad, Sayed Baqadar Shah Civil Hospital Matiari and Institute of chest diseases Kotri Sindh, Pakistan, (Vide Letter No: SBGH/L.ABAD HYD-1575; Dated: 13-04-17, LUH/Estt/-23,176/14; Dated: 06-08-2016, MSSGHQ/HYD/2187: Dated:13-04-17, CS/CH/MAT:1761; Dated:18-05-16 and ICDK 771; Dated: 12-04-17, respectively). Oral informed consent assent was acquired from every caregiver of children upon enlistment because of their illiterate status.

\section{Consent for publication}

Not applicable.

\section{Competing interests}

The authors declare that they have no competing interests.

\section{Publisher's Note}

Springer Nature remains neutral with regard to jurisdictional claims in published maps and institutional affiliations.

\section{Author details}

${ }^{1}$ Department of Clinical Pharmacy, School of Pharmaceutical Sciences, Universiti Sains Malaysia, 11800 Minden Penang, Malaysia. ${ }^{2}$ College of Pharmacy, Liaquat University of Medical and Health Sciences, Jamshoro 76090, Pakistan.

Received: 7 March 2018 Accepted: 9 January 2019

Published online: 24 January 2019

\section{References}

1. Jasmer R, Seaman C, Gonzalez L, Kawamura L, Osmond D, Daley C. Tuberculosis treatment outcomes directly observed therapy compared with self-administered therapy. Am J Respir Crit Care Med. 2004;170(5):561-6.

2. Faustini A, Hall A, Perucci C. Tuberculosis treatment outcomes in Europe: a systematic review. Eur Respir J. 2005;26(3):503-10. 
3. World Health Organization [WHO]. Treatment of tuberculosis: guidelines for National Programmes. In: Who/CDS/TB/2003, vol. 313. Switzerland: Geneva; 2003.

4. World Health Organization [WHO]. Global Tuberculosis Report 2017. Who/ HTM/TB/2017.23. Switzerland: Geneva; 2017.

5. National TB Control Program [NTP]. Annual Report 2016. In: IslamabadPakistan; 2016

6. World Health Organization [WHO]. Treatment of tuberculosis: guidelines. In: Who/HTM/TB/2009, vol. 426. Switzerland: Geneva; 2010

7. Gebrezgabiher G, Romha G, Ejeta E, Asebe G, Zemene E, Ameni G Treatment outcome of tuberculosis patients under directly observed treatment short course and factors affecting outcome in southern Ethiopia: a five-year retrospective study. PLoS One. 2016;11(2):e0150560.

8. Centers for Disease Control and Prevention NCFHS. Data Table of Weightfor-age Charts. Atlanta. USA: U.S. Department of Health \& Human Services HHS/Open USA.Gov; 2001.

9. World Health Organization [WHO]. Guidance for National Tuberculosis Programmes on the Management of Tuberculosis in children. In: Who/HTM/ TB/2014, vol. 03. Switzerland: Geneva; 2014.

10. National TB Control Program [NTP]. National Guidelines for the Managemnet of Tuberculosis in Pakistan. National TB control Programme, Ministry of Health, and Government of Pakistan. 2015. http://ntp.gov.pk/ uploads/deskguide_for_Doctors.pdf.

11. World Health Organization [WHO]. Definitions and reporting framework for tuberculosis - 2013 Revision (WHO/HTM/TB/2013.2). Switzerland: Geneva. p. 2013.

12. van Rie A, Beyers N, Gie R, Kunneke M, Zietsman L, Donald P. Childhood tuberculosis in an urban population in South Africa: burden and risk factor. Arch Dis Child. 1999;80(5):433-7.

13. Ade S, Harries A, Trébucq A, Ade G, Agodokpessi G, Adjonou C, et al. National profile and treatment outcomes of patients with extrapulmonary tuberculosis in Bénin. PLoS One. 2014;9(4):e95603.

14. Baghaie N, Khalilzade S, Boloursaz M, Khodayari A, Velayati A. Extra pulmonary tuberculosis in children: two years study. Acta Med Iran. 2010; 48(4):239-43.

15. van Well G, Paes B, Terwee C, Springer P, Roord J, Donald P, et al. Twenty years of pediatric tuberculous meningitis: a retrospective cohort study in the western cape of South Africa. Pediatric. 2009;123(1):e1-8.

16. World Health Organization [WHO]. Guidance for National Tuberculosis Programmes on the Management of Tuberculosis in children. (WHO/HTM) TB/2006. 371.Who/FCH/CAH/2006.7). Geneva, Switzerland. 2006.

17. Das J, Achakzai A, Bhutta Z. Stop stunting: Pakistan perspective on how this could be realized. Matern Child Nutr. 2016;12(Suppl 1):253-6.

18. Novignon J, Aboagye E, Agyemang O, Aryeetey G. Socioeconomic-related inequalities in child malnutrition: evidence from the Ghana multiple indicator cluster survey. Health Econ Rev. 2015;5(34):1-11.

19. Khan G, Turab A, Khan M, Rizvi A, Shaheen F, Ullah A. Et al. prevalence and associated factors of malnutrition among children under-five years in Sindh, Pakistan: a cross-sectional study. BMC Nutr. 2016;2(69).

20. Morris C, Bird A, Nell H. The haematological and biochemical changes in severe pulmonary tuberculosis. Q J Med. 1989;73(272):1151-9.

21. Nandennavar $\mathrm{M}^{\top}$, Cyriac S, Krishnakumar, Sagar T. Immune hemolytic Anemia in a patient with tuberculous lymphadenitis. J Glob Infect Dis 2011;3(1):89-91.

22. Hella J, Cercamondi Cl, Mhimbira F, Sasamalo M, Stoffel N, Zwahlen M, Bodmer T, Gagneux S, Reither K, Zimmermann MB, Risch L, Fenner L. Anemia in tuberculosis cases and household controls from Tanzania: contribution of disease, coinfections. and the role of hepcidin Plos One. 2018;13(4):e0195985.

23. Oyer R, Schlossberg D. Tuberculosis. New York: Springer, New York, NY; 1994.

24. Kony SJ, Hane AA, Larouzé B, Samb A, Cissoko S, Sow PS, Sané M, Maynart M, Diouf G, Murray JF. Tuberculosis-associated severe CD4+ Tlymphocytopenia in HIV-seronegative patients from Dakar. SIDAK research group. J Inf Secur. 2000;41(2):167-71.

25. Lowe D, Bandara A, Packe G, Barker R, Wilkinson R, Griffiths C, et al. Neutrophilia independently predicts death in tuberculosis. Eur Respir J. 2013;42(6):1752-7.

26. Lyadova I. Neutrophils in tuberculosis: heterogeneity shapes the way? Mediat Inflamm. 2017;2017:1-11.

27. World Health Organization [WHO]. Global Tuberculosis Report. Who/HTM/ TB/2013. Switzerland: Geneva; 2013. p. 11.
28. Tilahun G, Gebre-Selassie S. Treatment outcomes of childhood tuberculosis in Addis Ababa: a five-year retrospective analysis. BMC Public Health. 2016;16(612).

29. Osman M, Lee K, Preez K, Dunbar R, Hesseling A, Seddon J. Excellent treatment outcomes in children treated for tuberculosis under routine operational conditions in Cape Town. South Africa Clin Infect Dis. 2017; 65(9):1444-52.

30. Alavi S, Salmanzadeh S, Bakhtiyariniya P, Albagi A, Hemmatnia F, Alavi L. Prevalence and treatment outcome of pulmonary and extrapulmonary pediatric tuberculosis in southwestern Iran. Caspian J Intern Med. 2015;6(4):213-9.

31. Harries A, Hargreaves N, Graham S, Mwansambo C, Kazembe P, Broadhead $\mathrm{R}$, et al. Childhood tuberculosis in Malawi: nationwide case-finding and treatment outcomes. Int J Tuberc Lung Dis. 2002;6(5):424-31.

32. Flick RJ, Kim M, Simon K, Munthali A, Hosseinipour M, Rosenberg N, et al. Burden of disease and risk factors for death among children treated for tuberculosis in Malawi. Int J Tuberc Lung Dis. 2016;20(8):1046-54

33. Aketi L, Kashongwe Z, Kinsiona C, Fueza S, Kokolomami J, Bolie G, et al. Childhood tuberculosis in a sub-Saharan tertiary facility: epidemiology and factors associated with treatment outcome. PLoS One. 2016;11(4):e0153914.

34. Oeltmann J, Chengeta B, Mboya J, Wells C, Kilmarx P, Samandari T, et al. Reported childhood tuberculosis treatment outcomes, Gaborone and Francistown, Botswana, 1998-2002. Int J Tuberc Lung Dis. 2008;12(2):186-92.

35. Muñoz-Sellart M, Yassin M, Tumato M, Merid Y, Cuevas L. Treatment outcome in children with tuberculosis in southern Ethiopia. Scand J Infect Dis. 2009:41(6-7):450-5.

36. Kebede Z, Taye B, Matebe Y. Childhood tuberculosis: management and treatment outcomes among children in Northwest Ethiopia: a crosssectional study. Pan Afr Med J. 2017;27(25).

37. Adejumo O, Daniel O, Adebayo B, Adejumo E, Jaiyesimi E, Akang G, et al. Treatment outcomes of childhood TB in Lagos, Nigeria. J Trop Pediatr. 2016; 62:131-8.

38. Mtabho C, Irongo C, Boeree M, Aarnoutse R, Kibiki G. Childhood tuberculosis in the Kilimanjaro region: lessons from and for the TB Programme. Tropical Med Int Health. 2010;15(5):496-501.

39. Hailu D, Abegaz W, Belay M. Childhood tuberculosis and its treatment outcomes in Addis Ababa: a 5-years retrospective study. BMC Pediatr. 2014;14(61)

40. Nabukeera-Barungi N, Wilmshurst J, Rudzani M, Nuttall J. Presentation and outcome of tuberculous meningitis among children: experiences from a tertiary children's hospital. Afr Health Sci. 2014;14(1):143-9.

\section{Ready to submit your research? Choose BMC and benefit from:}

- fast, convenient online submission

- thorough peer review by experienced researchers in your field

- rapid publication on acceptance

- support for research data, including large and complex data types

- gold Open Access which fosters wider collaboration and increased citations

- maximum visibility for your research: over $100 \mathrm{M}$ website views per year

At $\mathrm{BMC}$, research is always in progress.

Learn more biomedcentral.com/submissions 